\title{
SMEs' Performance in Developing Countries: Suitability of Personal Wealth Measures
}

\author{
Kibeshi Kiyabo* Nsubili Isaga \\ School of Business, Mzumbe University, PO Box 6, Mzumbe, Morogoro, Tanzania
}

\begin{abstract}
This study tested the suitability of personal wealth in measuring SMEs' performance as compared to already known firm growth measures. Guided by the knowledge-based view, the study aimed at determining the influence of learning orientation on SMEs performance under the mediation of competitive advantage using firm growth and personal wealth measures. A structured questionnaire was used to collected data from 300 owners-managers of welding industry SMEs located in Dar es Salaam, Mbeya, and Morogoro urban centres in Tanzania. Measurement and structural models were developed by the aid of SmartPLS 3 software through application of structural equation modelling technique. Determination of indirect influence of learning orientation on SMEs' performance through competitive advantage was accomplished by bootstrapping the original sample using 5000 samples. Findings inform that competitive advantage mediates the relationship between learning orientation and SMEs' performance for both firm growth and personal wealth performance measures. This study has contributed to the understanding that learning orientation influences SMEs' performance under the mediation of competitive advantage using personal wealth as measures of SMEs' performance. The findings imply that the knowledgebased view is suitable in describing not only physical resources but also intangible resources such as learning orientation. Literature will benefit from future studies that will investigate the influence of other constructs on SMEs' performance under the mediation of competitive advantage using the same firm growth and personal wealth performance measures. Such studies will ascertain whether the findings of this study are specific to learning orientation construct or applicable to other constructs as well.
\end{abstract}

Keywords: Competitive advantage, firm growth, learning orientation, personal wealth, SMEs' performance

DOI: $10.7176 / \mathrm{EJBM} / 12-24-06$

Publication date:August $31^{\text {st }} 2020$

\section{Introduction}

SMEs' performance is an independent variable commonly used in entrepreneurship and strategic management studies. Despite its frequent use as a dependent variable, scholars have not yet agreed on its generic measures (Mahmood \& Hanafi 2013a; Mahmood \& Hanafi 2013b). As a result, measurement of SMEs' performance is still fragmented, the situation that leads to mixed results when studying the determinants or factors that influence SMEs' performance. Mixed results create an environment that pose threats towards comprehensive knowledge accumulation and theory building. However, financial performance measures such as growth in sales, number of employees, profit, assets and equity (Shepherd \& Wiklund 2009) are commonly used in literature. In addition to firm growth measures, non-financial performance measures are also used, these include but not limited to customers' satisfaction, customers' referral rate, growth in customers' base and market share (Chong 2008).

Together with the widespread use of financial and non-financial performance measures which have been developed in western countries, their effective use in developing countries such as Tanzania may be questionable. The uncertainty is triggered by differences in motives for establishing enterprises in western world and developing countries. The western world perceives an entrepreneur as an individual capable of innovatively identifying and exploiting resources and opportunities to produce value-added products or services; while, entrepreneurs in the developing countries, use their enterprises to obtain their daily bread for their lives (Eijdenberg 2016). While earnings from enterprises in western world are used to boost the firm growth, part of earnings from enterprises in developing countries is used to maintain the lives of entrepreneurs. Therefore, a need arises to use personal wealth performance measures in developing countries. However, validation of personal wealth performance measures calls for empirical evidence. Unfortunately, past studies have not provided empirical evidence on the suitability of personal wealth as performance measures hence this study.

Through application of the knowledge-based view, this study tested the suitability of personal wealth as SMEs' performance measures. The study adopted learning orientation (Calantone et al. 2002), competitive advantage (Ramaswami et al. 2006), and SMEs' performance (Shepherd \& Wiklund 2009; Eijdenberg 2016) as independent, mediating, and dependent variables respectively. The study concurrently used firm growth and personal wealth performance measures to facilitate comparison of results and hence establish whether personal wealth measures produce similar or different results as compared to already known firm growth performance measures.

The main objective of this study was to determine the influence of learning orientation on SMEs' performance under the mediation of competitive advantage using firm growth and personal wealth performance measures. Specifically, this study aimed (1) to determine the influence of learning orientation on competitive advantage, (2) 
to determine the influence of competitive advantage on SMEs' performance using both firm growth and personal wealth measures, (3) to determine the mediating effect of competitive advantage on the influence of learning orientation on SMEs' performance using both firm growth and personal wealth measures, and (4) to ascertain the suitability of personal wealth as performance measures.

This study adopted the quantitative research paradigm with cross-sectional design to collect data from owners-managers of welding industry SMEs located in urban centres of Dar es Salaam, Mbeya and Morogoro in Tanzania.

\section{Literature review}

\subsection{Theoretical review}

The resource-based view suggests that a firm's competitive advantage and superior performance emanate from the firm specific resources and capabilities that are costly for copying by rivals, valuable, rare, imperfectly imitable, and non-substitutable (Barney 1991). Generally, it is widely agreed that the resource-based view is one of the substantial theories of strategic management (Akio 2005; Barney et al. 2011; Connor 2002). However, critiques on the resource-based view have alarmed that the view has over-looked the role of entrepreneurial strategies and abilities as one of the crucial sources of competitive advantage of the firm (Akio 2005; Priem \& Butler 2001) and the view does not broadly explain how strategic assets are created or acquired (Connor 2002). Therefore, in order to alleviate the identified weaknesses of the resource-based view, the knowledge-based view has been introduced as its extension (Curado 2006).

The knowledge-based view basically insists on knowledge management through creation, storage, sharing, and deployment of knowledge across firm units (Theriou et al. 2009). Knowledge management can be achieved through learning, a process which is seen as a key element in creating competitive advantage and promotion of firm performance (Saarenketo et al. 2009; Al-Duwailah \& Hashem 2019; Apriliadi \& Adman 2019). Therefore, knowledge as a unique strategic resource creates and promotes firm performance.

In an attempt to operationalize knowledge management, this study found that learning orientation is an appropriate construct that can describe knowledge as a unique resource that is capable of creating competitive advantage to promote firm performance. Learning orientation refers to organization-wide activity of creating and using knowledge to enhance competitive advantage; it is a firm's degree of commitment to learning, shared vision, open-mindedness, and intra-organisational knowledge sharing (Calantone et al. 2002). Measures for competitive advantage were adopted from Ramaswami et al. (2006), Mahmood \& Hanafi (2013a), and Mahmood \& Hanafi (2013b). Firm growth measures were adopted from Sheperd \& Wiklund (2009) and personal wealth measures were adopted from Eijdenberg (2016). Figure 1 shows the conceptual framework that depicts the influence of learning orientation on SMEs' performance under the mediation of competitive advantage.

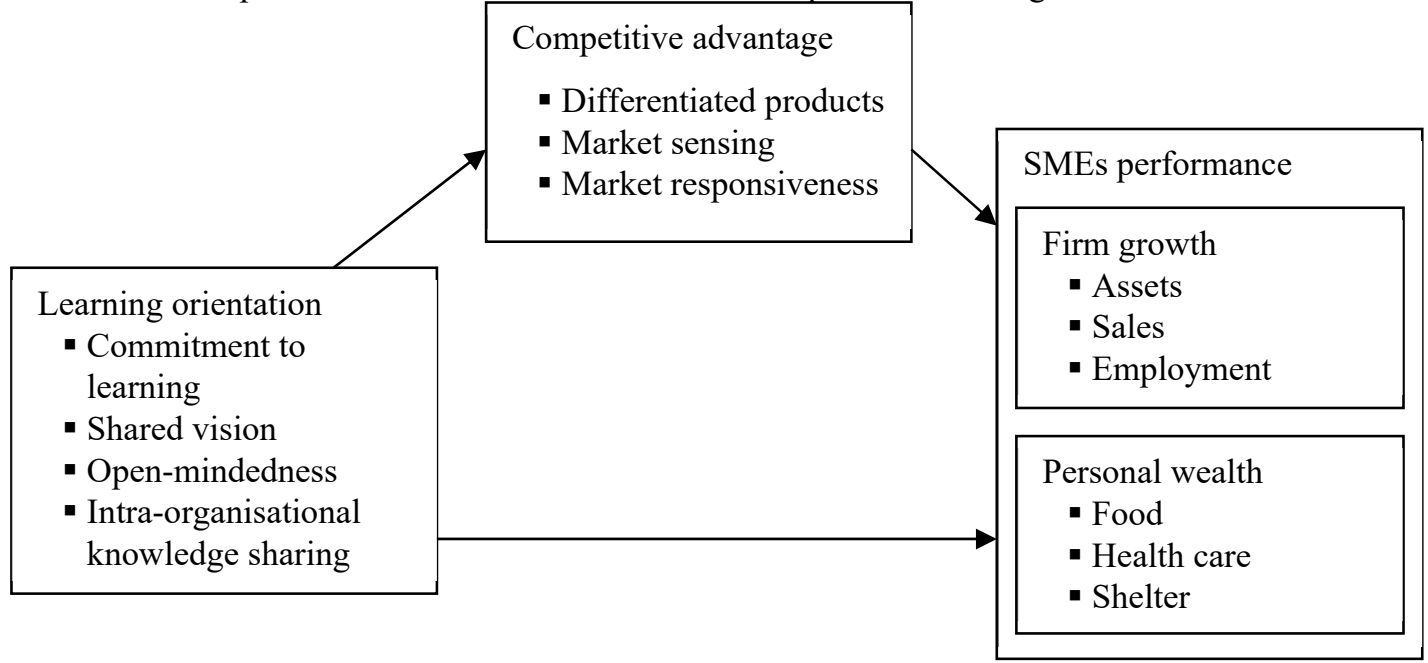

Figure 1. Conceptual framework

Source: Researchers' construct based on literature review

\subsection{Empirical review}

Firm resources include among others organizational processes that enable the firm to conceive a strategy that when implemented is able to improve the firm's efficiency and effectiveness (Barney, 1991). Learning orientation is a firm resource in form of processes which include creation and usage of knowledge for the sake of obtaining competitive advantage for superior performance. Learning orientation is normally measured using three dimensions which are commitment to learning, open-mindedness, and shared vision (Serna et al. 2018). In addition, 
intra-organisational knowledge sharing is another dimension of learning orientation which is used concurrently with the common three aforementioned dimensions (Calantone et al. 2002).

Although past studies have attempted to investigate the influence of learning orientation on SMEs' performance, consistency of results has not been achieved due to use of heterogeneous performance measures. For example, Yeni (2015) measured performance using five items which are increase in product volume, increase in profit, new product success in market, new entry to market places, and increase in number of customers for the past three years. Recently, Petty et al. (2019) measured performance using three items which are sales, assets, and number of employees for the past three years. Martinez et al. (2020) measured performance using items such as increase in sales, level of return on investment, level of benefits, customers' satisfaction, and employees' satisfaction for the past two years. In another study, Sawaean \& Ali (2020) measured performance using financial and operational measures. These few examples demonstrate that the scale of performance is fragmented which may be a possible cause for mixed results among studies investigating the relationship between learning orientation and SMEs' performance.

Despite the use of heterogeneous performance measures, positive and significant influence of learning orientation on SMEs' performance has been found in Yeni (2015), Hussain et al. (2018), Petty et al. (2019), and Sawaean \& Ali (2020). The work of Martinez et al. (2020) investigated the individual influences of learning orientation dimensions on SMEs' performance, findings inform that open-mindedness and commitment to learning dimensions positively and significantly influenced SMEs' performance while shared vision dimension of learning orientation negatively and significantly influenced SMEs' performance. While most past studies reported positive and significant influence of learning orientation on SMEs' performance, other studies like Serna et al. (2016) and Beneke et al. (2016) reported insignificant influence of learning orientation on SMEs' performance.

Although the mediating effect of competitive advantage on the relationship between learning orientation and SMEs performance is not yet extensively studied (Mahmood \& Hanafi 2013b), it has been shown that competitive advantage of a firm is positively and significantly influenced by learning orientation (Martinette \& ObenchainLeeson 2012). Furthermore, positive and significant influence of competitive advantage on SMEs performance has been reported (see for example Ismail et al. 2010; Majeed 2011; Muafi \& Roostika 2014; Wijetunge 2016; Zhou et al. 2009).

Based on the findings of theoretical and empirical literature review, this study hypothesizes that:

$\mathrm{H}_{1}$ : Learning orientation positively influences competitive advantage,

$\mathrm{H}_{2}$ : Competitive advantage positively influences SMEs' performance, and

$\mathrm{H}_{3}$ : Competitive advantage mediates the relationship between learning orientation and SMEs' performance.

\section{Methodology}

\subsection{Research design}

This study was conducted in Dar es Salaam, Mbeya and Morogoro urban centres of Tanzania. Data were collected from owners-managers of welding industry SMEs. The welding industry was selected due to its importance in joinery of metal and alloy materials (American Welding Society 2011). It produces together with other things grills for windows, doors, fence walls, and entrance gates in building construction works. Past studies on welding industry have addressed the technical and social aspects of the industry (Alkahla \& Pervaiz 2017) but literature on business aspect of the industry especially on strategic and entrepreneurial perspectives is still scanty not only in Tanzania but also worldwide. The study adopted a cross-sectional design with survey method. The sample size was determined by a rule of thumb based on the requirements of structural equation modelling and factor analysis techniques. Hair et al. (2010) suggested that a sample size of 120 subjects is sufficient for factor loadings \pm 0.5 or above. Furthermore, when structural equation modelling technique is used, each independent variable or predictor requires 15-20 observations (Hair et al. 2010).

This study used learning orientation and competitive advantage constructs as predictors of SMEs' performance. In addition, learning orientation construct was used as a predictor of competitive advantage construct. Learning orientation has 17 items and competitive advantage has 12 items. Thus, 17 is the highest number of items in the model. Multiplying 17 by a minimum number of observations (subjects), which is 15 yielded a minimum sample size of 255 subjects. Generally, the sample size between 100 and 400 subjects is deemed suitable for models that are developed using structural equation modelling (Hair et al. 2010). Thus, by using the rule of thumb, based on structural equation modelling and factor analysis requirements, a sample size of 300 subjects was considered sufficient for this study.

\subsection{Measurements of variables and data collection}

Measurement and structural models were developed using three constructs, these are learning orientation, competitive advantage and SMEs' performance. However, in order to enable comparison of results, SMEs' performance was measured using firm growth and personal wealth performance measures. Measurements of constructs were adopted from past studies as shown in Table 1. 
A structured questionnaire was used to collect data from owners-managers of welding industry SMEs in the research area. Constructs were measured using five points Likert scale. Respondents were asked to rate their agreement or disagreement to the questions (from "strongly disagree" $=1$ to "strongly agree" $=5$ ) for learning orientation, competitive advantage, and SMES' performance using firm growth measures for the past five years to December, 2016 as a base year. Furthermore, respondents were asked to rate the level of change of personal wealth measures for the past five years to December, 2016 using a five points scale from "a lot less" = 1 to "a lot more" $=5$.

Table 1. Measurement of model variables

\begin{tabular}{|c|c|c|c|}
\hline Construct & Dimension & $\begin{array}{l}\text { Number of } \\
\text { items }\end{array}$ & Source \\
\hline \multirow[t]{4}{*}{ Learning orientation } & Commitment to learning & Four & \multirow[t]{4}{*}{ Calantone et al. (2002) } \\
\hline & Shared vision & Four & \\
\hline & Open-mindedness & Four & \\
\hline & $\begin{array}{l}\text { Intra-organisational knowledge } \\
\text { sharing }\end{array}$ & Five & \\
\hline \multirow[t]{3}{*}{ Competitive advantage } & Differentiated products & Three & \multirow[t]{3}{*}{ Ramaswami et al. (2006) } \\
\hline & Market sensing & Four & \\
\hline & Market responsiveness & Five & \\
\hline \multirow{3}{*}{$\begin{array}{l}\text { SMEs' performance } \\
\text { (Growth measures) }\end{array}$} & Growth in assets & One & \multirow{3}{*}{$\begin{array}{l}\text { Shepherd \& Wiklund } \\
\text { (2009) }\end{array}$} \\
\hline & Growth in sales & One & \\
\hline & Growth in number of employees & One & \\
\hline \multirow{3}{*}{$\begin{array}{l}\text { SMEs' performance } \\
\text { (Personal wealth } \\
\text { measures) }\end{array}$} & Food purchasing capability & One & \multirow[t]{3}{*}{ Eijdenberg (2016) } \\
\hline & Health care paying capability & One & \\
\hline & Shelter acquisition capability & One & \\
\hline
\end{tabular}

Source: Researchers' tabulation based on literature review

\subsection{Data analysis}

Learning orientation and competitive are second order constructs and their dimensions are first order constructs (see Table 2). Total scores for dimensions of learning orientation and competitive advantage were computed using a statistical package for social sciences (SPSS) computer software for the sake of reducing the model complexity. The computed total scores transformed the dimensions into observed or manifest variables while learning orientation and competitive advantage were transformed into first order constructs. SMEs' performance measures for both firm growth and personal wealth are observed variables hence were not transformed. Table 2 shows the transformed variables and the associated abbreviations for total scores.

Aided by SmartPLS 3 computer software, this study developed two measurement models, one for firm growth performance measures and the other for personal wealth performance measures using confirmatory factor analysis (CFA) technique. Subsequently, two structural models, one for firm growth performance measures and the other for personal wealth performance measures were developed using structural equation modelling (SEM) technique.

Table 2. Transformed model constructs

\begin{tabular}{|l|l|l|}
\hline First order construct & Observed dimension & Abbreviation \\
\hline \multirow{4}{*}{ Learning orientation (LO) } & Commitment to learning & Total CLE \\
\cline { 2 - 3 } & Shared vision & Total SVI \\
\cline { 2 - 3 } & Open-mindedness & Total OMI \\
\cline { 2 - 3 } & Intra-organisational knowledge sharing & Total IOR \\
\hline \multirow{3}{*}{ Competitive advantage (CA) } & Differentiated products & Total DPR \\
\cline { 2 - 3 } & Market sensing & Total MSE \\
\cline { 2 - 3 } & Market responsiveness & Total MRE \\
\hline
\end{tabular}

Source: Researchers' tabulation based on literature review

In addition, sample data were bootstrapped using 5000 samples to determine the direct influence of learning orientation on competitive advantage, the direct influence of competitive advantage on SMEs' performance, and the indirect influence of learning orientation on SMEs' performance through competitive advantage.

\section{Results}

\subsection{Development of measurement models}

Measurement models for reflective indicators were developed using four stages, which include assessment of factor loadings, internal consistency reliability, convergent validity, and discriminant validity (Richter et al. 2016; Ali et al. 2018; Hair et al. 2019; Benitez et al. 2020). Two measurement models were developed, one for firm growth performance measures and the other for personal wealth performance measures. 


\subsubsection{Factor loadings}

Assessment of factor loadings on each construct revealed that differentiated products (Total DPR) dimension of competitive advantage (CA) had a factor loading of 0.242 for firm growth measures and 0.301 for personal wealth measures. Since the minimum acceptable factor loading is 0.708 (Hair et al. 2019; Benitez et al. 2020), the dimension was deleted from both models. The remaining factor loadings were higher than 0.708 except for shared vision (Total SVI) dimension of learning orientation (LO) which was 0.670 for firm growth measures and 0.666 for personal wealth measures. However, these values were not far away from the threshold value of 0.708 hence their deficiencies were ignored. Therefore, in exception of Total DPR dimension, all other dimensions were considered for further analysis for both measurement models. Factor loadings are shown by single headed arrows originating from each construct to observed items (dimensions), for example, the factor loading for Total CLE dimension of learning orientation construct is 0.788 in a firm growth measurement model (see Figure 2) and 0.793 in a personal wealth measurement model (see Figure 3).

4.1.2 Internal consistency reliability

Internal consistency reliability is normally assessed using Cronbach's alpha $(\alpha)$, Dijkstra and Henseler's rho-A $\left(\rho_{\mathrm{A}}\right)$, and composite reliability $(\mathrm{CR})$. The precision of Cronbach's alpha as a measure of internal consistency reliability is low as compared to $\rho_{\mathrm{A}}$ as the items are unweighted (Hair et al. 2019; Benitez et al. 2020). Despite its weakness, Cronbach's alpha can be used as a lower bound and composite reliability as the upper bound while $\rho_{\mathrm{A}}$ is the most likely value of internal consistency reliability (Hair et al. 2019; Benitez et al. 2020). Suitable reliability values range from 0.70 to 0.90 as too high values more than 0.95 are problematic and indicative of redundant items in the model (Hair et al. 2019). This study assessed internal consistency reliability using all three indicators that is Cronbach's alpha, rho-A, and composite reliability. Findings show that all values ranged between 0.617 and 0.916 (Table 3). It is interesting to note that all $\rho_{\mathrm{A}}$ values were within a range of 0.70 and 0.90 hence internal consistency reliability was achieved in both firm growth and personal wealth measurement models.

Table 3. Construct internal consistency reliability and convergent validity

\begin{tabular}{|c|c|c|c|c|c|c|c|c|c|}
\hline \multirow[t]{2}{*}{ Construct } & \multicolumn{4}{|c|}{ Firm growth measures } & \multirow[t]{2}{*}{ Construct } & \multicolumn{4}{|c|}{ Personal wealth measures } \\
\hline & $\alpha$ & $\rho_{A}$ & $\mathbf{C R}$ & AVE & & $\alpha$ & $\rho_{\mathrm{A}}$ & $\mathbf{C R}$ & AVE \\
\hline $\mathbf{C A}$ & 0.617 & 0.832 & 0.775 & 0.582 & $\mathbf{C A}$ & 0.817 & 0.820 & 0.916 & 0.845 \\
\hline LO & 0.816 & 0.847 & 0.878 & 0.646 & LO & 0.816 & 0.846 & 0.878 & 0.645 \\
\hline PER & 0.830 & 0.848 & 0.899 & 0.750 & PER & 0.771 & 0.771 & 0.869 & 0.689 \\
\hline
\end{tabular}

Source: SmartPLS 3 software output (Ringle et al. 2015)

\subsubsection{Convergent validity}

Construct convergent validity is the measure of the extent to which certain items measure the same underlying construct (Benitez et al. 2020). This study assessed construct convergent validity using average variance extracted (AVE) values. AVE values greater than 0.5 indicate good construct convergent validity (Hair et al. 2019; Benitez et al. 2020). Findings show that AVE values were between 0.582 and 0.845 which provide evidence that convergent validity was achieved for all constructs using both firm growth and personal wealth measures (see Table 3) 


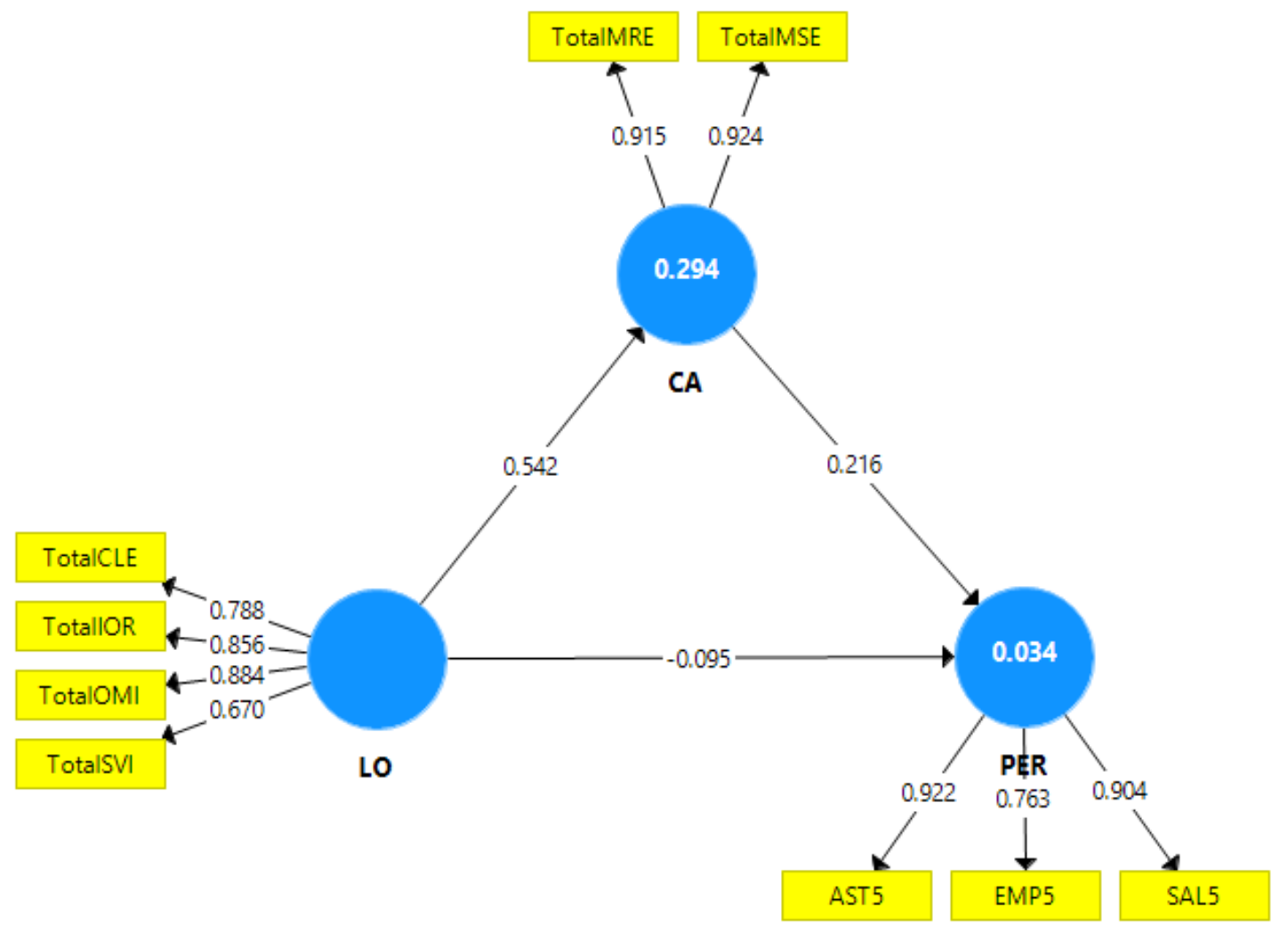

Figure 2. Measurement model for firm growth measures

4.1.4 Discriminant validity

Source: SmartPLS 3 software output (Ringle et al. 2015)

Assessment of discriminant validity ascertains whether one construct is distinct from another construct or not. Traditionally, the Fornell-Lacker criterion has been in use for a long time. However, recent studies have suggested that the criterion does not perform well when the factor loadings differ slightly, for example when factor loading range between 0.65 and 0.85 (Hair et al. 2019). Use of heterotrait-monotrait (HTMT) ratio of the correlations has been recommended to assess construct discriminant validity in lieu of the Fornell-Lacker criterion (Richter et al. 2016; Ali et al. 2018; Hair et al. 2019; Benitez et al. 2020). The HTMT is "the mean value of then item correlations across constructs relative to the (geometric) mean of the average correlations for the items measuring the same construct" (Hair et al. 2019, p. 9). Discriminant validity between any two constructs is achieved when the HTMT ratio of less than 0.90 exists (Hair et al. 2019; Benitez et al. 2020). Pursuant to the recent suggestions from extant literature, this study assessed construct discriminant validity using the HTMT ratio. Findings show that all HTMT ratios for all constructs for both firm growth and personal wealth measures were less than 0.90 confirming that constructs are unique or distinct from each other (Table 4). 


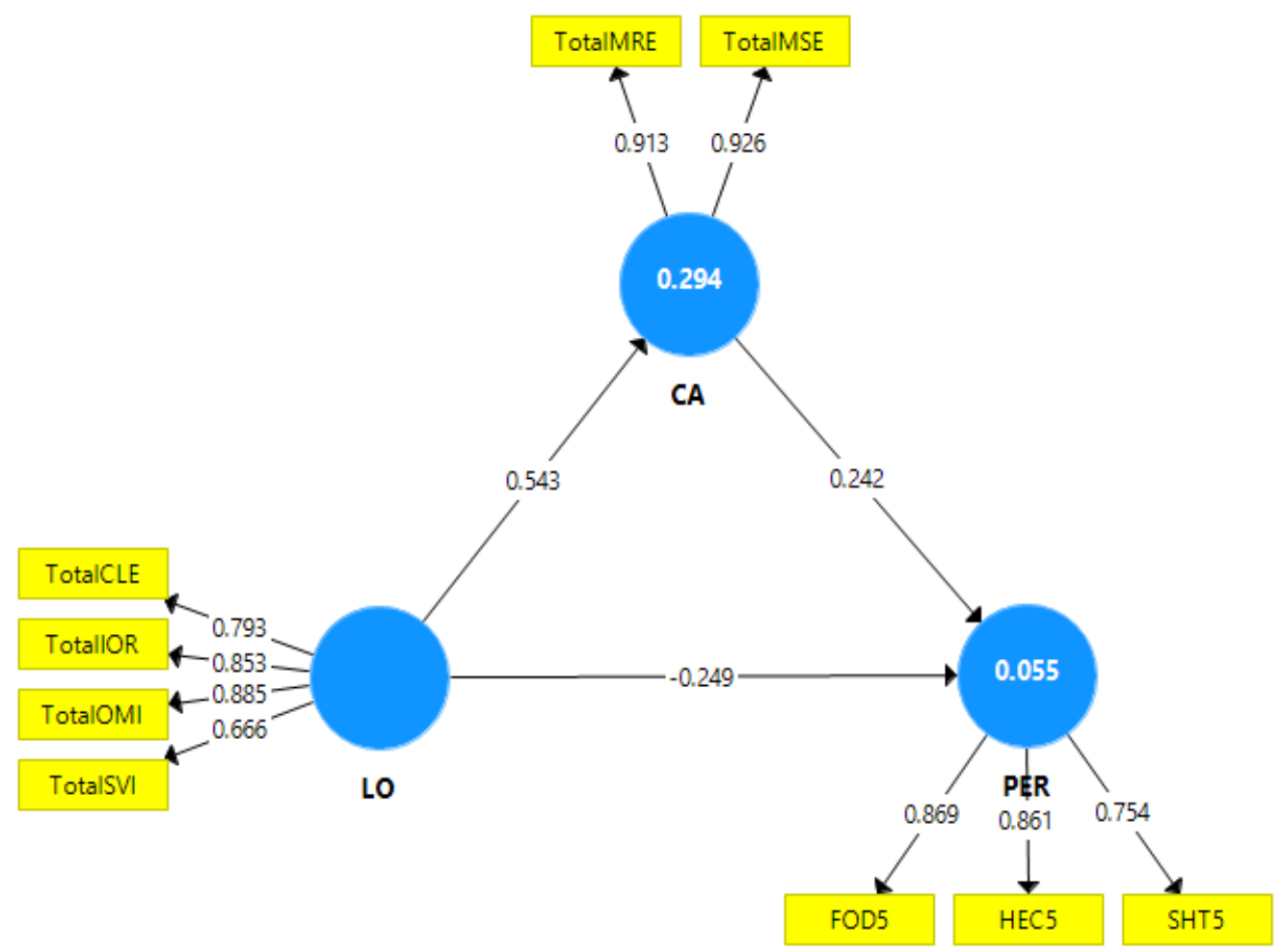

Figure 3. Measurement model for personal wealth measures Source: SmartPLS 3 software output (Ringle et al. 2015)

Table 4. Construct discriminant validity using HTMT ratio

\begin{tabular}{|l|l|l|l|l|l|l|l|}
\hline \multirow{2}{*}{ Construct } & \multicolumn{3}{|l|}{ Firm growth measures } & \multirow{2}{*}{ Construct } & \multicolumn{3}{|l|}{ Personal wealth measures } \\
\cline { 2 - 3 } \cline { 6 - 8 } & CA & LO & PER & & CA & LO & PER \\
\hline CA & - & & & CA & - & & \\
\hline LO & 0.699 & - & & LO & 0.649 & - & \\
\hline PER & 0.219 & 0.076 & - & PER & 0.136 & 0.152 & - \\
\hline
\end{tabular}

Source: SmartPLS 3 software output (Ringle et al. 2015)

\subsection{Hypotheses testing}

Aided by the SmartPLS 3 computer software, this study developed two structural measures, one for firm growth and the other for personal wealth performance measures. The models facilitated determination of the influence of learning orientation on competitive advantage and the influence of competitive advantage on SMEs' performance. Furthermore, the original sample was bootstrapped using 5000 samples to determine the mediating effect of competitive advantage on the relationship between learning orientation and SMEs' performance.

4.2.1 Assessment for collinearity

Prior to testing research hypotheses, structural models were assessed for collinearity (correlations among predictor variables) using variance inflation factor (VIF). Collinearity problems (multicollinearity) normally occur when VIF values are higher than 5 but the same may exist for VIF values between 3 and 5 (Hair et al. 2019; Benitez et al. 2020). Presence of multicollinearity among predictor variables may lead to insignificant path estimates and unanticipated weight signs (Benitez et al. 2020). Findings in the current study inform that all VIF values for all dimensions (items) for learning orientation and competitive advantage constructs were less than 3 hence no threat for presence of multicollinearity (Table 5).

Table 5. Assessment of collinearity

\begin{tabular}{|l|l|l|c|}
\hline Construct & Dimension (item) & Abbreviation & VIF \\
\hline \multirow{5}{*}{ Learning orientation } & Commitment to learning & Total CLE & 1.616 \\
\cline { 2 - 4 } & Shared vision & Total SVI & 1.392 \\
\cline { 2 - 4 } & Open mindedness & Total OMI & 2.307 \\
\cline { 2 - 4 } & Intra-organizational knowledge sharing & Total IOR & 2.068 \\
\hline \multirow{2}{*}{ Competitive advantage } & Market sensing & Total MRE & 1.911 \\
\cline { 2 - 4 } & Market responsiveness & Total MSE & 1.911 \\
\hline
\end{tabular}

Source: SmartPLS 3 software output (Ringle et al. 2015) 


\subsubsection{Path analysis on structural models}

The structural model for firm growth performance measures (Fig. 4) and personal wealth performance measures (Figure 5) show t-values for factor loadings and path coefficients. The factor loading or path coefficient is significant when the t-value is greater than 1.96 (the standardized $t$-value at 5\% level of significance). Results show that all factor loadings for all constructs have t-values greater than 1.96 hence significant. Path coefficients have t-values that are significant except the path between learning orientation and SMEs' performance whose tvalue is less than 1.96 for firm growth measures but the same path has t-value that is significant for personal wealth measures (see Figure 4 and Figure 5). Table 6 summarizes the hypotheses testing results.

Table 6. Hypotheses testing results for firm growth and personal wealth measures

\begin{tabular}{|c|c|c|c|c|c|}
\hline \multirow[t]{2}{*}{ No. } & \multirow[t]{2}{*}{ Hypothesis } & \multicolumn{4}{|c|}{ Firm growth measures } \\
\hline & & Coefficient $(\beta)$ & t-statistic & p-value & Decision \\
\hline $\mathrm{H}_{1}$ & $\mathrm{LO} \rightarrow \mathrm{CA}$ & 0.542 & 12.532 & 0.000 & Supported \\
\hline $\mathrm{H}_{2}$ & $\mathrm{CA} \rightarrow \mathrm{PER}$ & 0.220 & 2.961 & 0.003 & Supported \\
\hline $\mathrm{H}_{3}$ & $\mathrm{LO} \rightarrow \mathrm{CA} \rightarrow \mathrm{PER}$ & 0.119 & 2.883 & 0.004 & Supported \\
\hline \multirow[t]{2}{*}{ No. } & \multirow[t]{2}{*}{ Hypothesis } & \multicolumn{4}{|c|}{ Personal wealth measures } \\
\hline & & Coefficient $(\beta)$ & t-statistic & p-value & Decision \\
\hline $\mathrm{H} 1$ & $\mathrm{LO} \rightarrow \mathrm{CA}$ & 0.543 & 12.539 & 0.000 & Supported \\
\hline $\mathrm{H} 2$ & $\mathrm{CA} \rightarrow \mathrm{PER}$ & 0.243 & 3.027 & 0.002 & Supported \\
\hline H3 & $\mathrm{LO} \rightarrow \mathrm{CA} \rightarrow \mathrm{PER}$ & 0.132 & 2.898 & 0.004 & Supported \\
\hline
\end{tabular}

Source: SmartPLS 3 software output (Ringle et al. 2015)

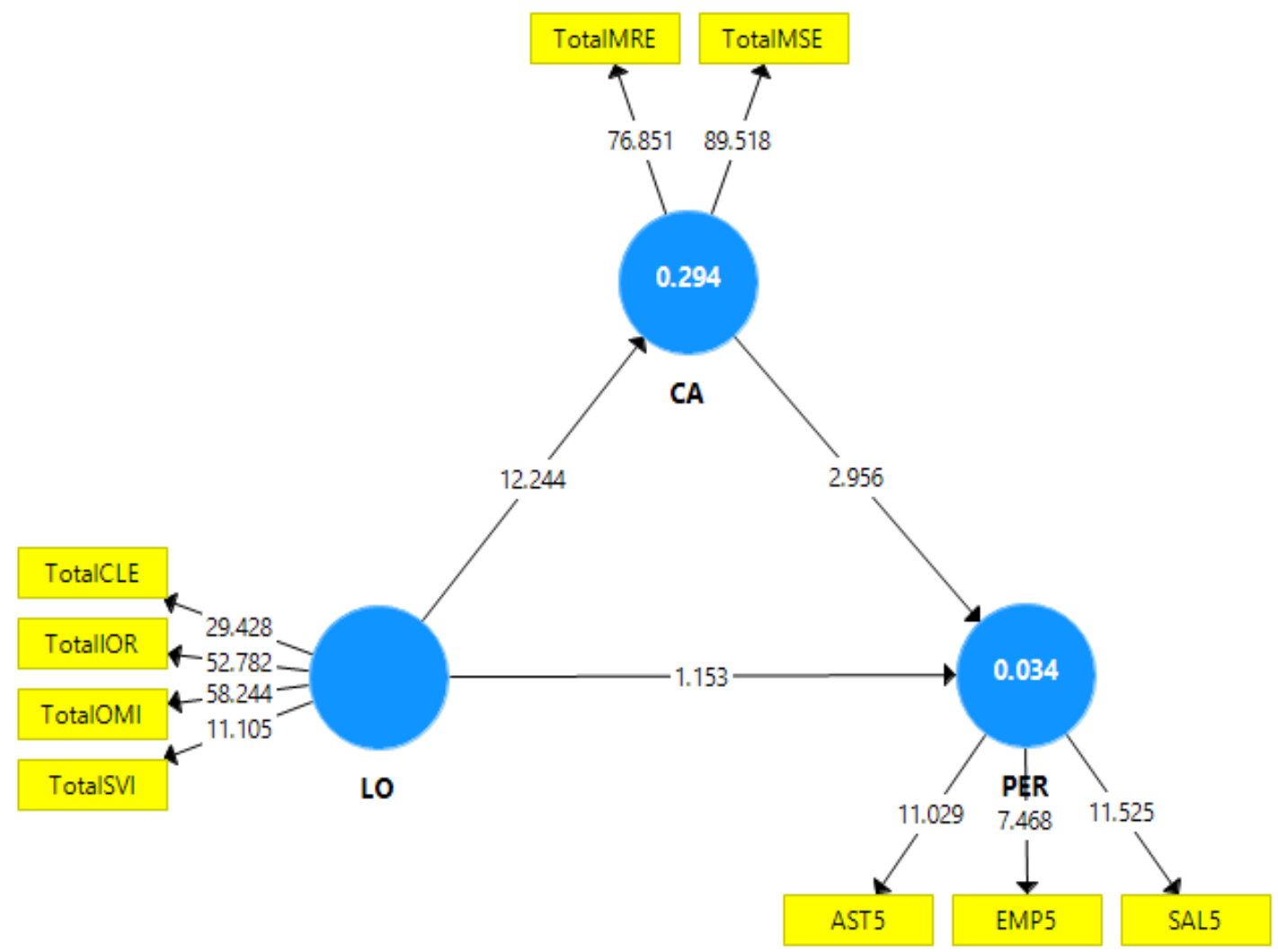

Figure 4. Structural model for firm growth measures

Source: SmartPLS 3 software output (Ringle et al. 2015)

This study formulated three hypotheses, these are: first, learning orientation positively influences competitive advantage, second, competitive advantage positively influences SMEs' performance, and third, competitive advantage mediates the relationship between learning orientation and SMEs' performance.

Findings show that regression coefficients for the direct influence of learning orientation on competitive advantage for firm growth and personal wealth performance measures are positive and significant, likewise, the regression coefficients for the influence of competitive advantage on SMEs' performance for firm growth and personal wealth performance measures are positive and significant and finally, the indirect influence of learning orientation on SMEs' performance through competitive advantage for firm growth and personal wealth performance measures are also positive and significant. These findings inform that hypotheses $\mathrm{H}_{1}, \mathrm{H}_{2}$, and $\mathrm{H}_{3}$ are all supported by the collected data. 


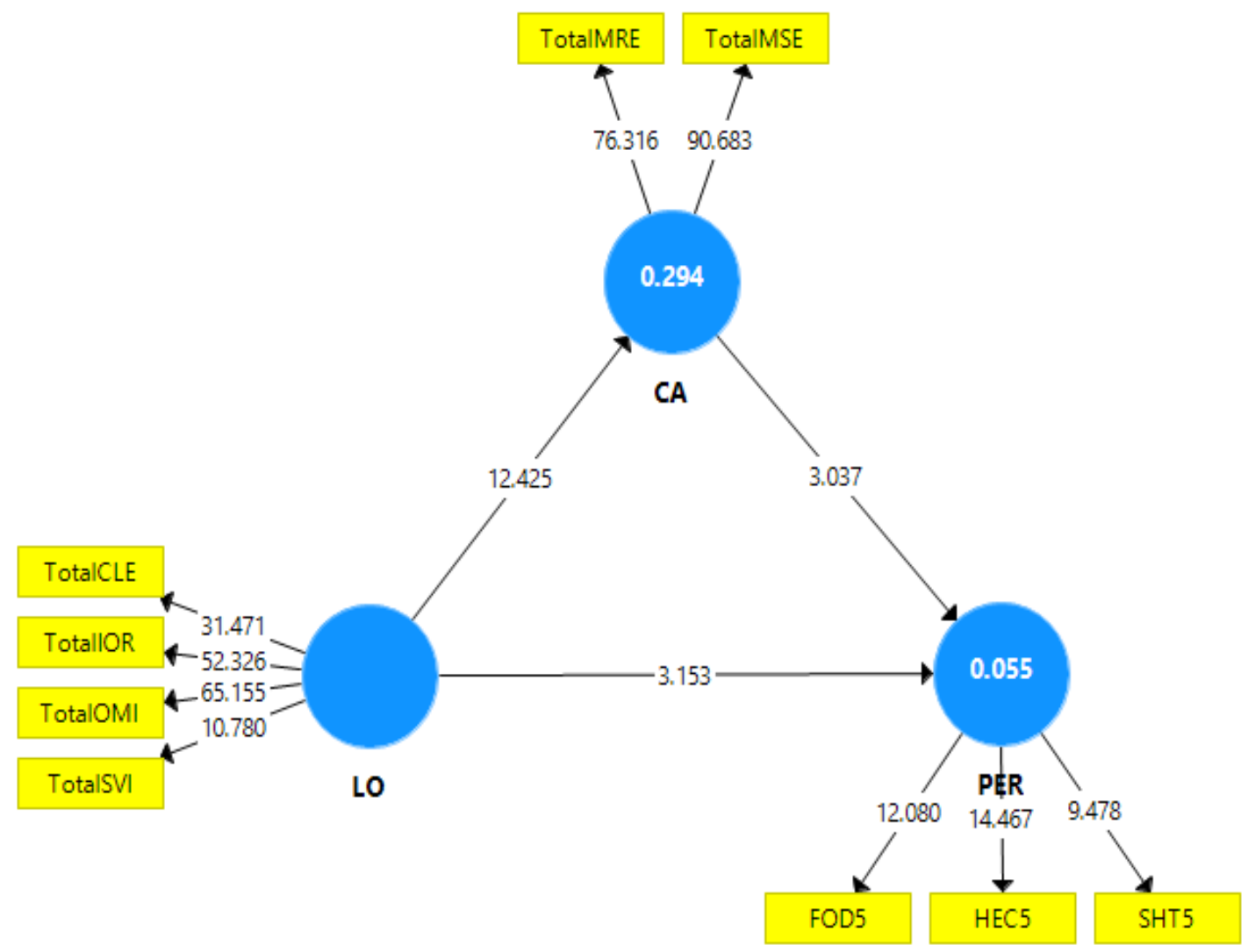

Figure 5. Structural model for personal wealth measures

Source: SmartPLS 3 software output (Ringle et al. 2015)

\section{Discussion}

This study aimed at determining the influence of learning orientation on SMEs' performance under the mediation of competitive advantage using firm growth and personal wealth performance measures. Use of firm growth and personal wealth performance measures facilitated comparison of the research findings to ascertain the suitability of personal wealth as SMEs' performance measures.

Guided by the knowledge-based view, the study developed a conceptual framework and eventually formulated three research hypotheses which were tested at 5\% level of significance using both the original sample and bootstrapped samples. In the first instance, learning orientation positively and significantly influenced competitive advantage. This finding is similar to the findings obtained by Martinez et al. (2020) in which openmindedness and commitment to learning dimensions of learning orientation positively and significantly influenced competitive advantage. The findings are also similar to the findings of Martinette \& Obenchain-Leeson (2012), and Mahmood \& Hanafi (2013b). These findings confirm that a firm that implements learning orientation creates competitive advantage over business rivals as per postulation of the knowledge-based view (Theriou et al. 2009).

In the second instance, this study found the positive and significant influence of competitive advantage on SMEs' performance using both firm growth and personal wealth measures. Based on firm growth performance measures, these findings are similar to those obtained in Ismail et al. (2010), Majeed (2011), Muafi \& Roostika (2014), Wijetunge (2016), and Zhou et al. (2009). These findings inform that the firm that creates competitive advantage promotes SMEs' performance for its survival and business excellence. These findings are in line with the knowledge-based view which suggests that competitive advantage is an important factor in promoting firm performance (Theriou et al. 2009). However, this study was unable to compare the personal wealth findings from past studies due to lack of studies that used such kind of SMEs' performance measures.

In the third instance, this study found that competitive advantage positively and significantly mediates the relationship between learning orientation and SMEs' performance. Based on firm growth performance measures, these findings have also been reported by Mahmood \& Hanafi (2013b). Likewise, this study was unable to compare the personal wealth findings from past studies due to lack of studies that used such kind of SMEs' performance measures.

Comparison of the findings derived from firm growth and personal wealth performance measures in this study informs that, the influence of learning orientation on competitive advantage, the influence of competitive advantage on SMEs' performance, and the indirect influence of learning orientation on SMEs' performance 
through competitive advantage are not far away for the two types of SMEs' performance measures (see Table 5). The coefficient values for all hypotheses are all positive and significant in both cases when firm growth and financial performance measures were used. The findings confirm that firm growth performance measures and personal wealth performance measures produced similar results, thus, it is evident that in addition to firm growth measures, personal wealth performance measures can be used in developing countries to measure SMEs' performance as proposed in Eijdenberg (2016).

\section{Conclusion, implication, and recommendations \\ 5.1 Conclusion}

Analysis of original sample and bootstrapped samples produced similar results when firm growth and personal wealth performance measures were used. Therefore, this study concludes that when both firm growth and personal wealth measures were used to reflect SMEs' performance: first; learning orientation positively and significantly influenced competitive advantage, second: competitive advantage positively and significantly influenced SMEs' performance, and third; competitive advantage mediated the influence of learning orientation on SMEs' performance. It is not disputed that firm growth performance measures have been developed and mostly used in western world, this study has confirmed that the measures are also applicable in developing countries like Tanzania. Although use of personal wealth performance measures seem to be a new approach in measuring SMEs' performance in developing countries, this study has produced empirical evidence that the measures are equally suitable like the firm growth measures.

\subsection{Contribution of the study}

Guided by the knowledge-based view, this study determined the influence of learning orientation on SMEs' performance under the mediation of competitive advantage. This study used firm growth and personal wealth measures to measure SMEs' performance in Tanzania's welding industry. Similar results were found for firm growth and personal wealth measures. Therefore, the study has contributed to the understanding that personal wealth measures comprising of food purchasing, health care paying, and shelter acquisition capabilities items are suitable in measuring SMEs' performance. Prior to the current study, to the best knowledge of the authors, past studies have not addressed this knowledge gap.

\subsection{Implication of the findings}

In accordance with the knowledge-based view, this study adopted learning orientation as a firm resource in form of processes (Barney 1991). Findings have shown that the influence of learning orientation on SMEs' performance is mediated by competitive advantage. The findings inform that the knowledge-based view is not only suitable in described tangible resources such as physical assets but also intangible resources such as learning orientation. In practice, intangible resources seem to drive firm performance much more than physical resources (Connor 2002). Therefore, in modern business, firm owners who invest not only in physical resources such as machineries but also in intangible resources such as learning orientation are likely to obtain competitive advantage for better performance.

Since SMEs in developing countries are established as an alternative to formal employment, most entrepreneurs depend on the firm earnings to sustain their lives and the associated accumulation of wealth as opposed to western world where entrepreneurs are driven by opportunities to be exploited (Eijdenberg 2016). Thus, measurement of SMEs' performance based on traditional indicators such as growth in sales, assets and number of employees may be supplemented by personal wealth performance measures. Having demonstrated that personal wealth performance measures are equally suitable just like firm growth performance measures, the findings of this study are expected to spark debates on the suitability of personal wealth as SMEs' performance measures across various industries and countries.

\subsection{Limitation of the study}

This study adopted a cross-sectional design by collecting data from owners-managers of welding industry SMEs' in Tanzania, thus, the findings are specific to the welding industry and cannot be generalized beyond it. Although competitive advantage can be defined using various dimensions, its definition in this study is limited to differentiated products, market sensing, and market responsiveness. Likewise, the definition of SMEs' performance is limited to the used firm growth (assets, sales, and employees) and personal wealth (food purchasing, health care paying, and shelter acquisition capabilities) measures.

\subsection{Recommendations}

The findings from this study have unveiled the suitability of personal wealth measures in measuring SMEs' performance in conjunction with firm growth measures. The study has demonstrated that personal earnings emanating from enterprises owned and managed by entrepreneurs are reliable measures of SMEs' performance. 
Therefore, the study recommends use of personal wealth measures in addition to well established firm growth measures. Use of personal wealth measures in developing countries is justified under the fact that entrepreneurs in those countries establish enterprises as an alternative to formal employment to sustain their daily lives.

Furthermore, this study investigated the influence of learning orientation on SMEs' performance under the mediation of competitive advantage using firm growth and personal wealth performance measures. Literature will undoubtedly benefit from future studies that will investigate the influence of other constructs on SMEs' performance under the mediation of competitive advantage using the same firm growth and personal wealth performance measures. Such studies will ascertain whether the findings of the current study are specific to learning orientation construct or applicable to other constructs as well. Additionally, research in other industries will also ascertain whether the findings of this study are specific to the welding industry or applicable to other industries as well.

\section{References}

Akio, T. (2005). The critical assessment of the Resource-Based View of strategic management: "The source of heterogeneity of the firm". Ritsumeikan International Affairs 3, 125-150.

Al-Duwailah, F. \& Hashem, T. N. (2019). "The Impact of knowledge management on CRM approaches". Management and Organizational Studies 6(1), 19-30.

Ali, F., Rasoolimanesh, F. M. Sarstedt, M., Ringle, C. M. \& Ryu, K. (2018). "An assessment of the use of partial least squares structural equation modeling (PLS-SEM) in hospitality research". International Journal of Contemporary Hospitality Management 30(1), 514-538.

Alkahla, I. \& Pervaiz, S. (2017). Sustainability assessment of shielded metal arc welding (SMAW) process. IOP Conf. Series: Materials Science and Engineering 244, 1-8.

American Welding Society [AWS] (2011). "Vision for welding industry". Retrieved March 28, 2016 from the World Wide Web: http://www.aws.org/library/doclib/vision.pdf

Apriliadi, A. \& Adman (2019). "The impact of knowledge management on SMEs performance in the city of Bandung". International Journal of Recent Technology and Engineering (IJRTE) 8(3S2), 550-557.

Barney, J. (1991). "Firm resources and sustained competitive advantage". Journal of Management 17(1), 99-120.

Barney, J. B., Ketchen, D. J. Jr. \& Wright, M. (2011). "The future of Resource-Based Theory: Revitalization or decline?” Journal of Management 37(5), 1299-1315.

Barret, P. (2007). "Structural equation modelling: adjudging model fit". Personality and Individual Differences 42, 815-824.

Beneke, J., Blampied, S., Dewar, N. \& Soriano, L. (2016). "The impact of market orientation and learning orientation on organisational performance: A study of small to medium-sized enterprises in Cape Town, South Africa". Journal of Research in Marketing and Entrepreneurship 18(1), 90-108.

Benitez, J., Henseler, J., Castillo, A. \& Schuberth, F. (2020). "How to perform and report an impactful analysis using partial least squares: Guidelines for confirmatory and explanatory IS research". Information \& Management 57, 1-16.

Calantone, R. J., Cavusgila, S. T. \& Zhao, Y. (2002). "Learning orientation, firm innovation capability, and firm performance". Industrial Marketing Management 31, 515-524.

Cepeda, G., Nitzl, C., \& Roldán, J. L. (2018). "Mediation analyses in partial least squares structural equation modeling: guidelines and empirical examples". In H. Latan \& R. Noonan (Eds.), Partial least squares structural equation modeling: basic concepts, methodological issues and applications. Heidelberg: Springer.

Chong, H. G. (2008). "Measuring performance of small-and-medium sized enterprises: the grounded theory approach". Journal of Business and Public Affairs 2(1), 1-10.

Connor, T. (2002). "The resource-based view of strategy and its value to practising managers". Strategic Change 11, 307-316.

Curado, C. (2006). "The knowledge based-view of the firm: from theoretical origins to future implications" (Working Paper 1). ISEG - Universidade Técnica de Lisboa.

Eijdenberg, E. L. (2016). "Does one size fit all? A look at entrepreneurial motivation and entrepreneurial orientation in the informal economy of Tanzania". International Journal of Entrepreneurial Behavior \& Research 22(6), 1-31.

Grant, R. M. (1996). “Toward a knowledge-based theory of the firm”. Strategic Management Journal 17(winter special issue), 109-122.

Hair, J. F. Jr., Black, W. C., Babin, B. J. \& Anderson, R. E. (2010). "Multivariate Data Analysis": Global Perspective. New Jersey: Pearson Prentice Hall.

Hair, J. F., Risher, J. J., Sarstedt, M. \& Ringle, C. M. (2019). "When to use and how to report the results of PLSSEM". European Business Review 31(1), 2-24.

Hussain, J., Shah, F. A., Rahman, W. \& Khan, Y. (2018). "Learning orientation and performance: the interaction effect of entrepreneurial orientation”. Pakistan Business Review January, 960-977. 
Ismail, A. I., Rose, R. C., Abdullah, H. \& Uli, J. (2010). "The relationship between organisational competitive advantage and performance moderated by the age and size of firms". Asian Academy of Management Journal 15(2), 157-173.

Mahmood, R. \& Hanafi, N. (2013a). "Entrepreneurial orientation and business performance of women-owned small and medium enterprises in Malaysia: Competitive advantage as a mediator". International Journal of Business and Social Science 4(1), 82-90.

Mahmood, R. \& Hanafi, N. (2013b). "Learning orientation and business performance of women-owned SMEs in Malaysia: The mediating effect of competitive advantage”. British Journal of Arts and Social Sciences 11(2), $150-161$.

Majeed, S. (2011). “The Impact of Competitive Advantage on Organizational Performance. European Journal of Business and Management 3(4), 191-196.

Martinette, L. A. \& Obenchain-Leeson, A. (2012). "The relationship between learning orientation and business performance and the moderating effect of competitive Advantage: A service organization perspective". Journal of Service Science 5(1), 43-58.

Martinez, J. E. V., Serna, M. C. M. \& Montoya, N. P. (2020). "Dimensions of learning orientation and its impact on organizational performance and competitiveness in SMEs". Journal of Business Economics and Management 21(2), 395-420.

Muafi, P. \& Roostika, R. (2014). "Organizational performance and competitive advantage determinants of creative SMEs". European Journal of Economics and Management 1(2). 7-25.

Petty, T. L., Francis, J. \& Wolf, J. A. (2019). "The interplay of strategic orientations and their influence on SME performance". Journal of Small Business Strategy 29(3), 46-59.

Priem, R. L. \& Butler, J. E. (2001). "Is the resource-based view a useful perspective for strategic management research?" Academy of Management Review 26(1), 22-40.

Ramaswami, S. N., Srivastava, R. \& Bhargava, M. (2006). "Market-based assets and capabilities, business processes, and financial performance". Emory University.

Richter, N. F., Sinkovics, R. R., Ringle, C. M. \& Schlägel, C. (2016). "A critical look at the use of SEM in international business research". International Marketing Review 33(3), 376-404.

Ringle, C. M., Wende, S., \& Becker, J. M. (2015). "SmartPLS 3". Boenningstedt: SmartPLS GmbH, http://www.smartpls.com.

Saarenketo, S., Puumalainen, K., Kuivalainen, O. \& Kylaheiko, K. (2009). "A knowledge-based view of growth in new ventures". European Business Review 21(6), 531-546.

Sawaean, F. A. A. \& Ali, K. A. M. (2020). "The impact of entrepreneurial leadership and learning orientation on organizational performance of SMEs: The mediating role of innovation capacity". Management Science Letters 10, 369-380.

Serna, M. C. M., Martinez, J. E. V. \& Martinez, J. V. (2016). "The impact of learning orientation on innovation and performance in SMEs in México". International Review of Management and Business Research 5(1), 4864.

Serna, M. C. M., Martinez, J. E. V. \& Domenech, V. E. (2018). "The influence of organizational commitment and learning orientation on innovation in SMEs". Contaduría y Administración, 63 (3), 1-19.

Shepherd, D. \& Wiklund, J. (2009). "Are we comparing apples with apples or apples with oranges? Appropriateness of knowledge accumulation across growth studies". Entrepreneurship Theory and Practice 33(1), 105-123.

Theriou, N. G., Aggelidis, V. \& Theriou, G. N. (2009). "A theoretical framework contrasting the resource-based perspective and the knowledge-based view". European Research Studies 12(3), 177-190.

Wijetunge, W. A. D. S. (2016). "Service quality, competitive advantage and business performance in service providing SMEs in Sri Lanka”. International Journal of Scientific and Research Publications 6(7), 720-728.

Yeni, Y. H. (2015). "The influence of entrepreneurial orientation and learning orientation on firm performance of MSMEs in west Sumatra". Paper presented at the Australasian conference on business and social sciences. Sydney.

Zhou, K. Z., Brown, J. R. \& Dev, C. S. (2009). "Market orientation, competitive advantage, and performance: A demand-based perspective". Journal of Business Research 62(11), 1063-1070. 